\title{
COPD and Public Opinion: Results of a Survey in the General Population
}

\section{Dal Negro RW ${ }^{1^{*}}$, Guerriero $\mathbf{M}^{2}$ and Turco $\mathbf{P}^{3}$}

${ }^{1}$ National Center for Respiratoy Pharmacoenomics and Pharmacoepidemiology - CESFAR, Verona, Italy

${ }^{2}$ Department of Computer Science, University of Verona, Italy

${ }^{3}$ Research \& Clinical Governance - R\&CG, Verona, Italy

\begin{abstract}
The assessment of public opinion's belief represents an important instrument in order to evaluate the best actions aimed at the containment of all conditions of substantial social impact.
\end{abstract}

Aim: Aim of the study was to investigate the current awareness and the perception of COPD in the Italian general population.

Methods: the opinion survey was carried out by means of the Computer Assisted Telephone Interviewing Technique (CATI). A pre-determined set of ten simple closed questions aimed to investigate the subjects' basic knowledge and awareness on COPD was the operational instrument.

Results: respondents were 1,170 individuals, representative of the national general population. The final redemption rate of the survey was $14 \%$, such as one successful interview out of 7 attempts: this result is clearly mirroring the poor appeal of COPD in the public opinion. The observed prevalence of COPD was very close to that officially known (5-6\%). Both the public knowledge and awareness of COPD determinants proved quite confused, except for smoking. The convincements of the majority of respondents were inconsistent, particularly as concerning the intrinsic severity; the duration, and the progression of COPD. People proved particularly unaware of the social and the economic impact of COPD. "Chronic Obstructive Pulmonary Disease" represented a terminology very difficult for espondents: they frequently stopped the call because they did not understand and feared these terms. The final suggestion is that the public belief on COPD still is limited to a few convincements emotionally driven, but not based on a true knowledge of the disease, particularly within younger individuals, who are the most unaware, but also the major responsible of the future burdening of COPD.

Keywords: COPD; Awareness; Opinion survey; General population; Public opinion

\section{Introduction}

Chronic Obstructive Pulmonary Disease (COPD) is a pathological condition characterized by a various extent of chronic airway obstruction and parenchimal deterioration that is not fully reversible [1]. COPD is also clinically characterized by progressive dyspnoea and decline in lung function; occurrence of acute exacerbations, and the presence of numerous comorbidities that may complicate and aggravate its progression [2].

COPD is a major cause of morbidity and mortality worldwide, with a prevalence of approximately $6 \%$ in the Italian general population [3-5]. The impact of COPD is remarkable and still growing, and it should be differently detailed: from the society point of view, because COPD-related mortality is presumed to play a relevant role in the near future (such as, the third cause of death in 2020) [6]; from the patients' perspective because COPD greatly limits their daily, occupational, and relational activities, and may frequently lead to a substantial disability; from the physician's perspective, who is increasingly consulted and involved, and finally from the perspective of the National Health Service (NHS), given the huge burden caused by the high and still increasing amount of resources absorbed by COPD [4,7-9].

The role of "public awareness" is strategic for stimulating the alert against whatever event or disease of social impact, and the assessment of the public opinion's belief represents an important instrument in order to investigate, understand and adapt the most appropriate and proactive actions aimed at the disease containment.

The phenomenon of COPD under-esteem is still debated since long ago: actually, both the current unacceptable delay in its diagnosis as well as its unacceptable under-treatment once diagnosed [10-12] are strongly suggesting the persistence of a substantial unawareness of COPD in the medical community, and consequently also in the public opinion.

Although the concept of "public awareness" has been increasingly evoked for COPD [10,13-16], true investigations oriented to its quantitative assessment within the public opinion still are episodic [17-19], or absent in our country. The aim of the present study was to investigate the knowledge and the awareness of COPD in the Italian general population.

\section{Methods}

The method of the opinion survey was used for investigation [20], and citizens were interviewed by means of a telephone call. Interviews were performed from May 15 to June 30, 2012 by using the Computer Assisted Telephone Interviewing Technique (CATI) [21-24]. All respondents were also characterized by age; gender; geographical distribution, current job, and educational level. The principal instrument used by investigators to collect data was a questionnaire. In particular, each interview was based on a pre-determined set of ten simple closed questions aimed to assess the subjects' basic knowledge and perception of COPD: possible answers were: "Yes"; "No"; "doubtful", except for question n.8, for which subjects were required to quantify COPD duration (such as, in weeks, or in months, or in years) (Table 1). All interviews were always preceded by a short explanation of the aim of the survey and by a short description of COPD.

The interviewer was provided with one "work station" consisting of a personal computer connected to a central processing unit. The central

*Corresponding author: Roberto Dal, National Center for Respiratoy Pharmacoenomics and Pharmacoepidemiology-CESFAR, Verona, Italy, Tel: 0039-348-3168888; E-mail: robertodalnegro@gmail.com

Received October 27, 2014; Accepted April 06, 2015; Published April 10, 2015

Citation: Dal Negro RW, Guerriero M, Turco P (2015) COPD and Public Opinion: Results of a Survey in the General Population. J Pulm Respir Med 5: 255 doi:10.4172/2161-105X.1000255

Copyright: ( $) 2015$ Dal Negro RW, et al. This is an open-access article distributed under the terms of the Creative Commons Attribution License, which permits unrestricted use, distribution, and reproduction in any medium, provided the original author and source are credited. 
unit was also equipped with a specific software for the random choice of individuals (such as, the phone numbers) to contact. Compared to a conventional telephone interview, the CATI technique also allowed to randomize the questions to put. Moreover, this system worked as a supervisor of the interviewer's activity: if the interviewer forgot some questions or even an entire section of the questionnaire, the PC would have alert him, thus avoiding errors due to missed questions.

As previously mentioned, the sampling strategy adopted in the present survey was the random selection of a number of subjects from each of the homogenous subgroups in which the population had been previously divided (such as, by geographical distribution, gender, and age); the main steps of the study plan are summarized in Figure 1.

Preliminary calculations of the sampling fixed at a minimum of 1,015 the number of contacts needed to achieve the representativity of the sample (by $3 \%$ maximum error, and $95 \%$ probability) [21].

\section{Results}

\section{The general profile of respondents}

The cohort of respondents consisted in a total of 1,170 individuals who fitted the general characteristics of Italian general population in terms of gender, age, and geographical distribution. In particular, women were $56.9 \%$ of respondents. The sample's mean age was 47.3 years (coefficient of variation $(\mathrm{CV})=38 \%$ ), by a median age of 43.2 years (Inter-Quartile Range $(\mathrm{IQR})=26.4$ years), and a modal age of 35.1 years; the last indicator informed that 35 -year-old people were those who, more than others, agreed to the interview. The age grouping confirmed the current age shift of Italian population towards older ages: actually, there were 163 over-65years for every 100 young individuals. From the point of view of schooling, the majority of respondents had got a diploma from middle or a vocational school (Table 2), in good agreement with general national data [5].

The most diffuse occupational activities were: clerks (25.2\%); senior officials or managers (16.6\%); housewives (15.4\%). The proportion of retired people was $19.3 \%$, while that of unemployed was low $3.9 \%$, and that of blue collars and students was 10.4 and $9.2 \%$, respectively (Table 2); finally, 160 unemployed were found for every 100 employed individuals. Obviously, these percentages do not reflect exactly the present national situation, but they only attain to those individuals who had given their consent to the phone interview during the survey.As concerning the geographical distribution of respondents, they were well regionally matched, and their distribution fits with the 2012 official data o residents both in terms of micro and macro geographical areas (Table 2).

The proportion of active smokers was $20.4 \%$, while ex-smokers were $21.0 \%$, and smokers were found to consume an average of 14.9 pack-

\begin{tabular}{|c|l|}
\hline $\begin{array}{c}\text { Serial } \\
\text { number }\end{array}$ & Question \\
\hline Q1 & $\begin{array}{l}\text { Did you ever heard about Chronic Obstructive Pulmonary disease } \\
\text { (COPD)? }\end{array}$ \\
\hline Q2 & tn your opinion, is COPD caused by ageing exclusively? \\
\hline Q3 & n your opinion, is COPD more costly than lung cancer for the society? \\
\hline Q4 & In your opinion, does cigarette smoking affect COPD? \\
\hline Q5 & $\begin{array}{l}\text { In your opinion, is COPD definitively curable with a short course of } \\
\text { antibiotics? }\end{array}$ \\
\hline Q6 & In your opinion, is COPD a rare disease? \\
\hline Q7 & In your opinion, how long can the duration of COPD be presumed? \\
\hline Q8 & In your opinion, can COPD exacerbate? \\
\hline Q9 & In your opinion, can COPD lead to disability? \\
\hline Q10 & Are you suffering from COPD? \\
\hline
\end{tabular}

Table 1: The set of questions.

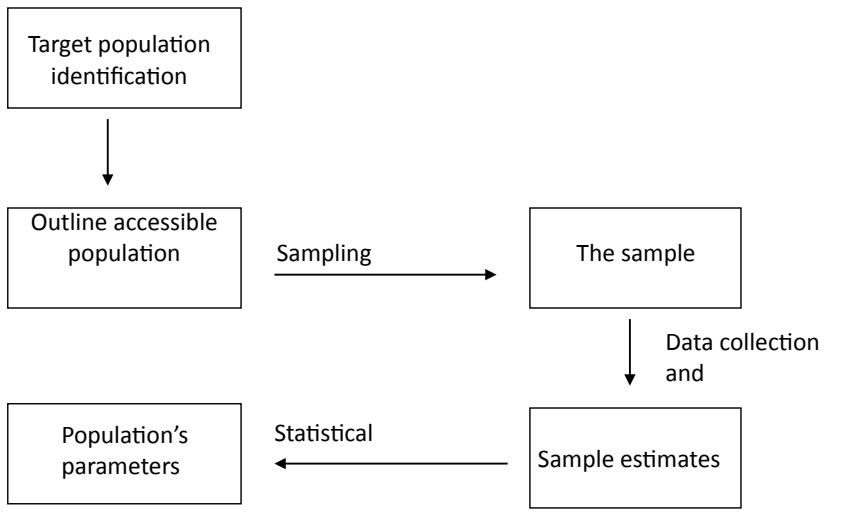

Figure 1: The steps of the statistical sample survey.

\begin{tabular}{|c|c|}
\hline $\mathbf{N}$ & 1,170 \\
\hline Males & 43.1 \\
\hline Females & 56.9 \\
\hline \multicolumn{2}{|l|}{ Age } \\
\hline Mean age & $47.3 \mathrm{yrs}$ \\
\hline Young/>65 yrs ratio & $1 / 1.63$ \\
\hline \multicolumn{2}{|l|}{ Smoke } \\
\hline Active & $20.40 \%$ \\
\hline Ex & $21.00 \%$ \\
\hline Never & $58.60 \%$ \\
\hline \multicolumn{2}{|l|}{ Educational level } \\
\hline Degree & $16.10 \%$ \\
\hline Middle school & $41.20 \%$ \\
\hline High school & $42.70 \%$ \\
\hline \multicolumn{2}{|l|}{ Job } \\
\hline Clerks & $25.20 \%$ \\
\hline Managers & $16.60 \%$ \\
\hline Housewives & $15.40 \%$ \\
\hline Retired & $19.30 \%$ \\
\hline Blue collars & $10.40 \%$ \\
\hline Students & $9.20 \%$ \\
\hline Unemplyed & $3.90 \%$ \\
\hline \multicolumn{2}{|l|}{ Regional distribution } \\
\hline North & $47.30 \%$ \\
\hline Center & $22.20 \%$ \\
\hline South & $30.50 \%$ \\
\hline
\end{tabular}

Table 2: The general profile of respondents.

year: also these figures are in agreement with those reported by the Italian Statistical Yearbook 2012 [5] for the general population, and they contribute to further support the good representativity of the cohort (Table 2).

\section{The analytical profile of respondents}

Male gender was prevalent in young people ( $<40$ years), but not in those $>60$ years. Graduation was equally prevalent in both genders, even if a lower educational degree was more frequent in females. In general, the educational profile was related and inversely proportional to the respondents' age; in addition, male gender was prevailing in several work activities, except in clerks and housewives. In general, the typical respondent was an employed female; 43 years of age; white collar, and with middle school level. As concerning the smoking habit, male gender still was slightly prevailing in the cohort (53.1\%), although more males than females 
tended to quit smoking (58.1 and $44.7 \%$, respectively). Cigarette smoking was a phenomenon which characterized younger respondents $(24.8 \%)$; adults (23.6\%); blue collars (25.8\%), and students (26.6\%), particularly in the southern regions. On the other hand, smoking cessation characterized adults $(52.2 \%)$; older people (56.7\%); retired $(57.9 \%)$, and unemployed subjects (51.4\%), particularly in the northern and central regions, being the interval 40-60 years the threshold line.

Furthermore, the percentage of those who affirmed to have already "heard" of COPD was 50\%, and data of the present study concerning both the knowledge and the awareness on COPD should be referred only to those respondents, who were further investigated by means of the remaining nine specific questions. However, this percentage was higher in the southern regions and in females $(36.6 \%)$, regardless of the respondents' age. On the contrary, the majority of students (66.9\%) affirmed they had never heard anything about COPD.

In general, the percentage of those who claimed to suffer from COPD was directly related to their age. In particular, males more than females; older more than younger people, and even more retired persons regarded $\mathrm{COPD}$ as an uniquely ageing-related condition, while both genders proved equally aware of the relationship between COPD and cigarette smoking, irrespective of their job. A proportion of $25.9 \%$ of individuals who claimed to suffer from COPD also affirmed to fear a possible hospitalization due to COPD. Women, particularly those retired and the housewives, reported to suffer from COPD in greater proportion than men $(4.6 \%$ and $3.7 \%$, respectively), and highly feared a possible hospitalization due to COPD (44.6\% and 38.9\%, respectively). Younger and older subjects mostly feared hospitalization ( $41.4 \%$ and $44.5 \%$, respectively), as well as the job categories of clerks, blue collars and students, particularly those from southern regions. In general, individuals who claimed to suffer from COPD were $4.0 \%$, while a further $1.9 \%$ declared to be doubtful: these figures are in good agreement with the Italian prevalence of COPD $(6 \%)$ officially communicated by the National Institute for Statistics [5]. Moreover, the $8.4 \%$ of citizens claimed to have someone suffering from COPD in their family (which is a sort of further indirect confirmation of the prevalence of COPD in general population), while $54.2 \%$ of subjects declared that they had never heard anything about COPD, and $13.6 \%$ were doubtful.

As concerning the major determinants of COPD, $75.6 \%$ of subjects affirmed that COPD is strictly related to smoking habit, while $53.3 \%$ of subjects were convinced that COPD is uniquely caused by ageing, and $10 \%$ were doubtful. Moreover, $40.1 \%$ of citizens regarded COPD as a "rare disease" (and 8.2\% were doubtful), and 51.7\% of interviewed were convinced that a short course of antibiotic therapy would be enough to cure this condition definitively. On the other hand, COPD was considered a disorder of short duration and without any future consequence by $35.9 \%$ of general population, while $42.8 \%$ of respondents affirmed that the duration of COPD could be longer than 10 years.A proportion of $46.1 \%$ of respondents was completely unaware about the possible occurrence of exacerbations during the natural history of COPD, and $61.0 \%$ was unaware of the possible (or frequent) progression of COPD to disability. It is noteworthy to note that particularly females $(38.7 \%)$ tended to consider more likely the occurrence of exacerbations during the history of COPD, and presume a possible progression of COPD towards disability. As concerning the impact of COPD, $76.0 \%$ of respondents was convinced that the social burden of COPD is extremely lower than that of lung cancer.

However, the overall perception of COPD impact was higher among respondents from the southern regions; in particular, this perception did not prove significantly related to their age or gender, but mostly to their job (such as: clerks, housewives and retired persons). The distribution of response to the main questions is summarized in Figure 2.
Finally, the redemption rate of the present survey (such as, the success rate of the phone interviews) was $14 \%$ : in other terms, one successful interview out of 7 attempts. In particular, it was much more difficult to obtain a successful interview from men than from women $(12.6 \%$ and $16.2 \%$, respectively), particularly from the southern regions and, curiously, from older individuals (13.1\%) than from adults and younger subjects (15.2\% and $15.9 \%$, respectively).

\section{Discussion}

The perception of "public opinion" is a crucial issue to face, and the assessment of both the "overall knowledge" and the "public awareness" of relevant social phenomena in real life represent a critical point. However, these measures are extremely helpful tools in order to assess the degree of alert against whatever disease condition, and for fitting the most appropriate and proactive actions aimed at containing that condition or disease.

Unfortunately, COPD proved poorly appealing for general population in the present survey, and this aspect is clearly and easily mirrored by the redemption rate achieved, which is extremely low (1 interview out of 7 attempts) when compared to that of similar surveys (an average of 33$25 \%$, such as 1 interview out of 3-4 calls) [23]. Nevertheless, it should be considered that in recent years telephone users had been frequently or daily targeted by companies operating in telephone marketing, whose purpose is to advertise and sell different products. The net result was that this strategy leaded to ever increasing difficulties in obtaining data via telephone calls, and general population became quite intolerant, suspicious and indifferent to a wide range of topics, including those which would be of great interest for their community.

However, COPD was completely unknown in $50 \%$ of respondents, and this proportion is quite impressive for a chronic pathological condition of such a severe social dimension as COPD is since long ago. Also the knowledge on COPD confirmed poor. Actually, even if a proportion of respondents claimed to be aware of the dangerous role of cigarette smoke (which in the present survey was regarded as the most relevant risk factor for COPD, as well as in other studies $[8,19,24])$, another relevant proportion of respondents claimed their firm belief that COPD is uniquely induced by ageing, even if they regarded COPD as a "rare disease", having this convincement been affirmed independently of their awareness of the wide diffusion of smoking habit. Moreover, a further set of respondents proved astonishingly convinced that COPD represents a pathological condition which is easily and definitively curable by means of a short-term antibiotic course: obviously, COPD does not represent a problem for the

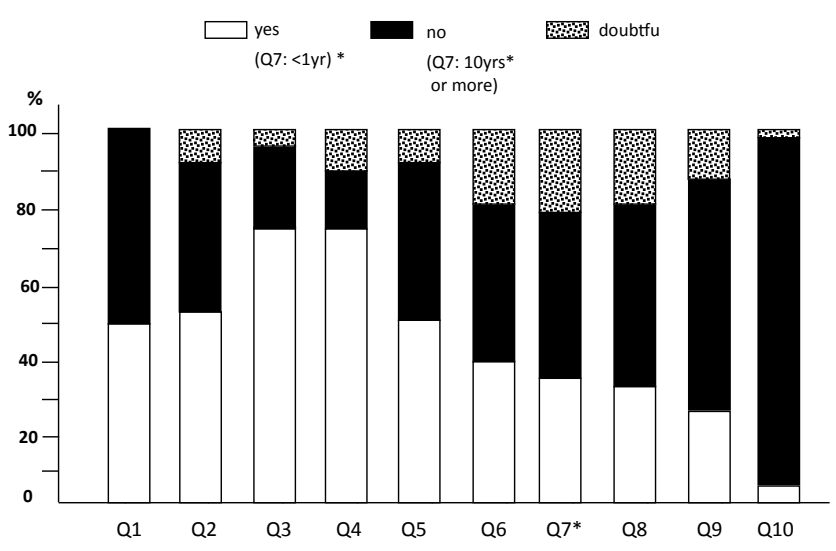

Figure 2: The \% distribution of response. 
public welfare at all in their opinion.

When considering the present effective burden of COPD, these convincement (which were claimed by the majority of respondents) are dramatically stressing the worrying distance existing between the current public belief on COPD and such a severe problem of public health for the entire community in real life [8]. However, even if the determinants of the disease are poorly perceived (or just for this reason), the psychological impact of COPD proved pretty high in public opinion. This is likely related to the suggestion of the possible occurrence of one or more hospitalizations, even though the vast majority of respondents claimed to ignore almost absolutely the problem of COPD progression and of its possible progression to disability in many cases.

In other words, public opinion tends to perceive the impact of BPCO mainly stemming from unknown and emotional elements rather than from a few cardinal points of knowledge. A further confirmation of this suggestion also comes out when considering that the public belief on COPD duration was extremely variable (such as changing from "a few days" up to "for ever"). On the other hand, variable was also the public belief on COPD progression, because it was regarded as a transient disorder by at least one third of respondents. A similar vision came out from the GARD Turkey Survey on Asthma and COPD where $51.1 \%$ of interviewed indicated that smoking is an important risk factor, but $49.6 \%$ of subjects knew that COPD is a lung disease [24].

Moreover, even if the majority of respondents affirmed a possible progression to disability, they provided a widespread, inconsistent response concerning the socio-economic impact of COPD which was considered extremely lower than that of lung cancer, even if the latter is unfortunately characterized by a much shorter duration than that of COPD in the majority of cases.

Independently of the social and cultural level of respondents, a great proportion of them did not prove any attitude to accept the principle of a long-term therapeutic strategy for COPD. This vision is obviously strictly linked to convincements previously mentioned and mainly regarding COPD as a transient disorder: obviously, this belief will further contribute to the dangerous under-esteem of COPD which likely still represents the major obstacle for the disease containment in our opinion.

As a consequence, taking into account the relative young age of respondents and stemming from their basic convincements, it can be easily presumed that no future preventive strategy against COPD and no effective therapeutic action for changing its natural history will be expected by the great proportion of general population, because almost completely unaware of the risk. It is then presumable that this vision will lead to a further burdening of COPD in the next future, both in epidemiologic and socio-economic terms.

Finally, to pinpoint that when the topic of "chronic obstructive pulmonary disease" was introduced by the interviewers at the start of each telephone call, these terms frequently led to the rejection or interruption of the interview by many respondents (as confirmed by the poor redemption rate achieved in the present survey) because they were perceived as too complex; they were mis-understood or not understood several times, then feared, and finally rejected. In our opinion, the scientific community should identify a strategy in order to find out also a new name, possibly allowing an easier and widespread comprehension of COPD within the general population. This would certainly ensure a direct and more effective approach to this global problem also by public opinion.

\section{Conclusions}

COPD is poorly perceived by the general population which is still denouncing a too insufficient degree of knowledge and awareness on this widespread chronic respiratory condition. Data from the present survey are also stimulating a much more effective empowerment and a much more capillary involvement of decision makers in order to greatly improve, together with the scientific community, the messages targeting public opinion on COPD, particularly within younger citizens who are representing the most unaware portion of our society on the topic, but nonetheless will cause the major social and economic impact of COPD in the next future.

\section{References}

1. Global Initiative for Chronic Obstructive Lung Disease. Global strategy for the diagnosis, management, and prevention of chronic obstructive pulmonary disease.

2. Anecchino C, Rossi E, Fanizza C, De Rosa M, Tognoni G, et al. (2007) Prevalence of chronic obstructive pulmonary disease and pattern of comorbidities in a general population. Int J Chron Obstruct Pulmon Dis 2: 567574

3. Viegi G, Scognamiglio A, Baldacci S, Pistelli F, Carrozzi L (2001) Epidemiology of chronic obstructive pulmonary disease (COPD). Respiration 68: 4-19.

4. Italian Statistical Yearbook 2012, ISTAT, Roma, 18 dicembre.

5. Murray CJ, Lopez AD (1997) Alternative projections of mortality and disability by cause 1990-2020: Global Burden of Disease Study. Lancet 349: 1498-1504

6. Vermeire $P$ (2002) The burden of chronic obstructive pulmonary disease Respir Med 96 Suppl C: S3-10.

7. Dal Negro RW, Micheletto C, Tosatto R, Dionisi M, Turco P, et al. (2007) Costs of asthma in Italy: results of the SIRIO (Social Impact of Respiratory Integrated Outcomes) study. Respir Med 101: 2511-2519.

8. Gibson GJ, Loddenkemper R, Lundbäck B, Sibille Y (2013) Respiratory health and disease in Europe: the new European Lung White Book. Eur Respir J 42 559-563.

9. Dal Negro RW, Bonadiman L, Turco P (2004) Current annual cost calculation is the best predictor of mortality at three years in COPD. International Society for Pharmacoeconomics and Outcomes Research - ISPOR, European Annual Meeting, Amsterdam.

10. Yawn BP, Kaplan A (2008) Co-morbidities in people with COPD: a result of multiple diseases, or multiple manifestations of smoking and reactive inflammation? Prim Care Respir J 17: 199-205.

11. Walters JA, Hansen EC, Walters EH, Wood-Baker R (2008) Under-diagnosis of chronic obstructive pulmonary disease: a qualitative study in primary care. Respir Med 102: 738-743.

12. Heffner JE, Mularski RA, Calverley PM (2010) COPD performance measures: missing opportunities for improving care. Chest 137: 1181-1189.

13. Holt K (2004) Improving early detection of COPD: the role of spirometry screening assessment. Prof Nurse 20: 31-33.

14. Rabe KF, Hurd S, Anzueto A, Barnes PJ, Buist SA, et al. (2007) Global strategy for the diagnosis, management, and prevention of chronic obstructive pulmonary disease: GOLD executive summary. Am J Respir Crit Care Med 176: 532-555.

15. CollectifCapital Souffle (2007)[Capital Souffle: results of a 2005 public awareness campaign about breath measurements in France]. Presse Med 36: 824-831.

16. Pederson AP, Hoyak KA, Mills S, Camp PG (2007) Reflecting the changing face of chronic obstructive pulmonary disease: sex and gender in public education materials on COPD. Proc Am Thorac Soc 4: 683-685.

17. Yıldız F, Bingöl Karakoç G, Ersu Hamutçu R, Yardım N, Ekıncı B, et al. (2013) [The evaluation of asthma and COPD awareness in Turkey (GARD Turkey Project-National Control Program of Chronic Airway Diseases)]. Tuberk Toraks 61: 175-182.

18. Decramer M, Brusselle G, Buffels J, Corhay JL, De Backer W, et al. (2013) COPD awareness survey: do Belgian pulmonary physicians comply with the GOLD guidelines 2010? Acta Clin Belg 68: 325-340. 
Citation: Dal Negro RW, Guerriero M, Turco P (2015) COPD and Public Opinion: Results of a Survey in the General Population. J Pulm Respir Med 5: 255. doi:10.4172/2161-105X.1000255

Page 5 of 5

19. Sanguinetti CM, De Benedetto F, Donner CF, Nardini S, Visconti A (2014) Pneumocafé project: an inquiry on current COPD diagnosis and management among General Practitioners in Italy through a novel tool for professional education. Multidiscip Respir Med 9: 35

20. Cicchitelli G, Herzel A, Montanari GE (1992) II campionamento statistico, II Mulino Edn, Bologna.

21. Franch M, Mich L e D'Elia M (2000) Ricerche di mercato online e sviluppo di nuovi prodotti e nuovi servizi. Risultati di alcune sperimentazioni, Università degli Studi di Trento.

22. Kraut R, Brynin M, Kiesler S (2006) Computers, phones, and the internet: domesticating information technology, Oxford University Press, Oxford.

23. Marbach G (2006) Ricerche per il marketing, UTET Ed, Torino.

24. Groves RM (1998) Telephone survey methodology, Wiley Publ., New York. 